\title{
Microwave assisted synthesis of benzophenone and acetophenone ethylene ketals
}

\author{
Gyula Lukács, ${ }^{\text {a* }}$ Márta Porcs-Makkay, ${ }^{\text {a }}$ Anna Komáromi, ${ }^{b}$ and Gyula Simiga \\ ${ }^{a}$ Chemical Research Division, EGIS Pharmaceuticals PLC., P.O. Box 100, 1475 Budapest, \\ Hungary \\ ${ }^{b}$ Budapest University of Technology and Economics, P.O. Box 91, 1521 Budapest, Hungary \\ E-mail:gy.lukacs@freemail.hu
}

\section{Dedicated to Professor Csaba Szántay on the occasion of his 80th birthday}

\begin{abstract}
A simple and convenient synthesis of acetophenone and benzophenone ethylene ketals was elaborated by performing the reaction of ethylene glycol in toluene in the presence of PTSA, under microwave irradiation with simultaneous removal of the water so formed. Under these conditions $100 \%$ conversion and high yields were obtained within short reaction times.
\end{abstract}

Keywords: Microwave heating, protecting groups, 1,3-dioxolanes, ketones, acetophenones, benzophenones

\section{Introduction}

Recently we have reported the lithiation reactions of chloro substituted acetophenones and benzophenones protected as 1,3-dioxolanes (1, Scheme 1). ${ }^{[1,2]}$ The lithio species 2 thus formed were treated with various electrophiles to give ortho-functionalized acetophenone derivatives $\mathbf{3}$, which provided precursors of a series of benzannelated heterocyclic systems 4 .

\footnotetext{
${ }^{*}$ Corresponding author. Tel.: +36-1-2655555/1693;
} 


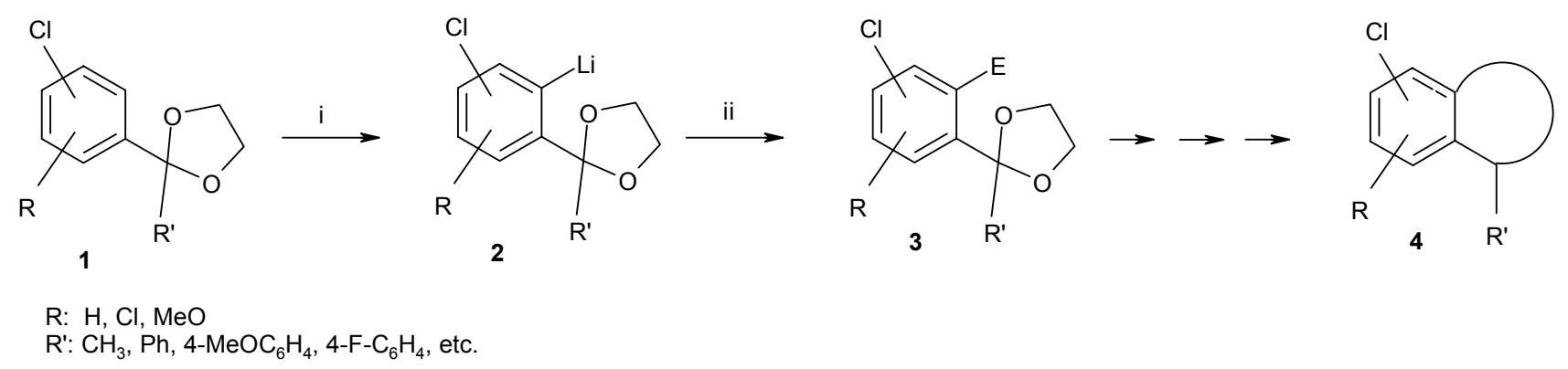

Reaction conditions: (i) butyllithium; (ii) electrophilic reagent;
\[ \mathrm{E}: \mathrm{COOH}, \mathrm{SO}_{2} \mathrm{Cl}, \mathrm{CH}_{3}, \mathrm{CHO} \]

\section{Scheme 1}

The ethylene ketals 1 have been prepared by the traditional method: long refluxing $(40 \mathrm{~h})$ of a solution of the ketone, ethylene glycol and para-toluenesulfonic acid (PTSA) in toluene with azeotropic removal of the water. ${ }^{[3-8]}$

We were seeking a simple and environmentally benign synthesis of benzophenone and acetophenone ethylene ketals. Most of the reported methods that avoided the drawbacks of the traditional protection methods (eg. long reaction times) resulted in procedures having other undesired features (reagents hazardous to the environment, limited scope, etc.). ${ }^{\left[{ }^{[}\right]}$

Some contradictory results have been published on the reaction of acetophenone and benzophenone with ethylene glycol without solvent in a microwave reactor. The irradiation of a mixture of acetophenone, ethylene glycol ( 10 equiv.) and PTSA (0.015 equiv.) in a "nonmodified domestic microwave oven" for two minutes has been described to afford the corresponding 1,3-dioxolan-2-yl derivative in $71 \%$ yield. ${ }^{[10]}$ This paper does not discuss the reaction of benzophenones under similar conditions. However, in another study, the mixture of acetophenone or benzophenone and ethylene glycol (2 equiv.) and PTSA (0.1 equiv.) was irradiated in a Prolabo (Synthewave ${ }^{\circledR}$ ) oven for 30 minutes (the monitored temperature $120{ }^{\circ} \mathrm{C}$ with a maximum emitted power of $120 \mathrm{~W}$ ), a low conversion $(20 \%)$ was observed with acetophenone, whereas, benzophenone did not react at all. ${ }^{[1]}$ Ketalization of some acetophenones with ethylene glycol has been described in a Teflon cylinder under microwave irradiation in the presence of water in 30-80 \% yield, however, the results are not supported by sufficient evidence to be considered reliable. ${ }^{[12]}$

In this paper we describe a simple and convenient synthesis of acetophenone and benzophenone ethylene ketals by performing the reaction of the starting materials with ethylene glycol in toluene in the presence of PTSA under microwave irradiation and with simultaneous removal of the so formed water. The apparatus used for the irradiations was the same as in the case of the traditional heating (eg. oil bath), except that the reaction flask was placed in the internal space of a microwave instrument (Figure 1). 


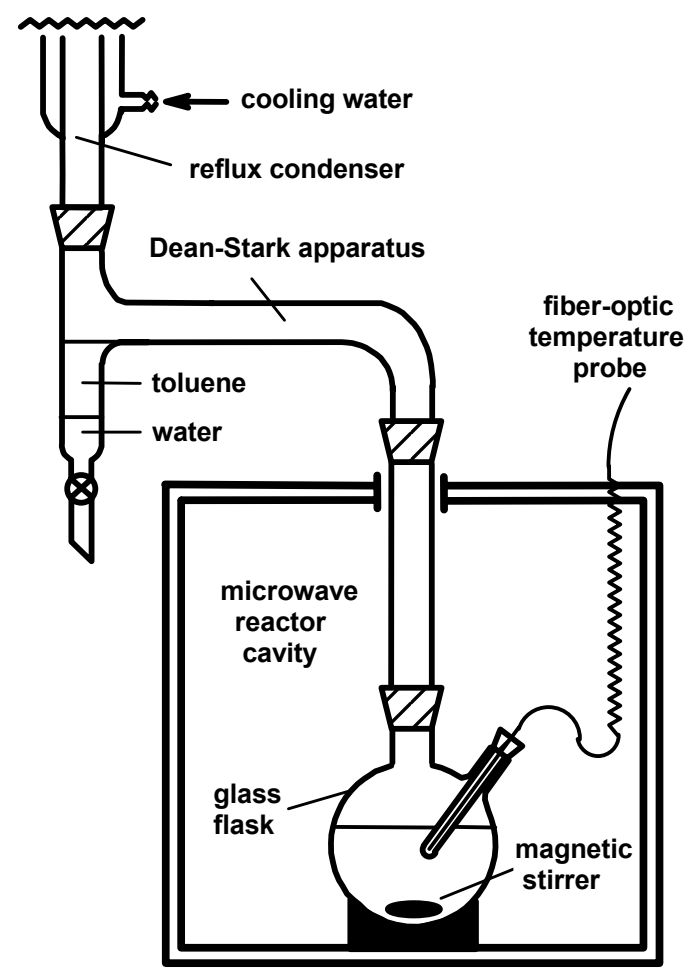

Figure 1. Schematic drawing of the experimental apparatus.

\section{Results and Discussion}

The conversion of 4-chlorobenzophenone (5a) into the corresponding 1,3-dioxolan-2-yl derivative $\mathbf{6 a}^{[2]}$ has been studied in detail. The mixture of ketone 5a (0.1 mol, Scheme 1), ethylene glycol $(31.0 \mathrm{~g}, 27.9 \mathrm{~mL}, 0.5 \mathrm{~mol})$, PTSA $(0.57 \mathrm{~g}, 0.003 \mathrm{~mol})$ and toluene $(140 \mathrm{~mL})$ in a round bottomed glass vessel equipped with a Dean-Stark apparatus was irradiated with constant $500 \mathrm{~W}$ energy in a Milestone MicroSYNTH ${ }^{\circledR}$ microwave reactor (Figure 1). Small samples were analysed by ${ }^{1} \mathrm{H}$ NMR to determine the conversion. ${ }^{[13]}$ After $3 \mathrm{~h}$ the conversion was complete (Figure 2) and the crystalline product was isolated in $98 \%$ yield. For comparison the reaction was also carried out under traditional conditions. A $42 \%$ conversion was achieved after $3 \mathrm{~h}$ by refluxing the mixture without irradiation and completion of the reaction took $40 \mathrm{~h}$. No superheating effect was observed under microwave conditions, as the boiling temperature was the same (113-114 $\left.{ }^{\circ} \mathrm{C}\right)$ in both cases. 


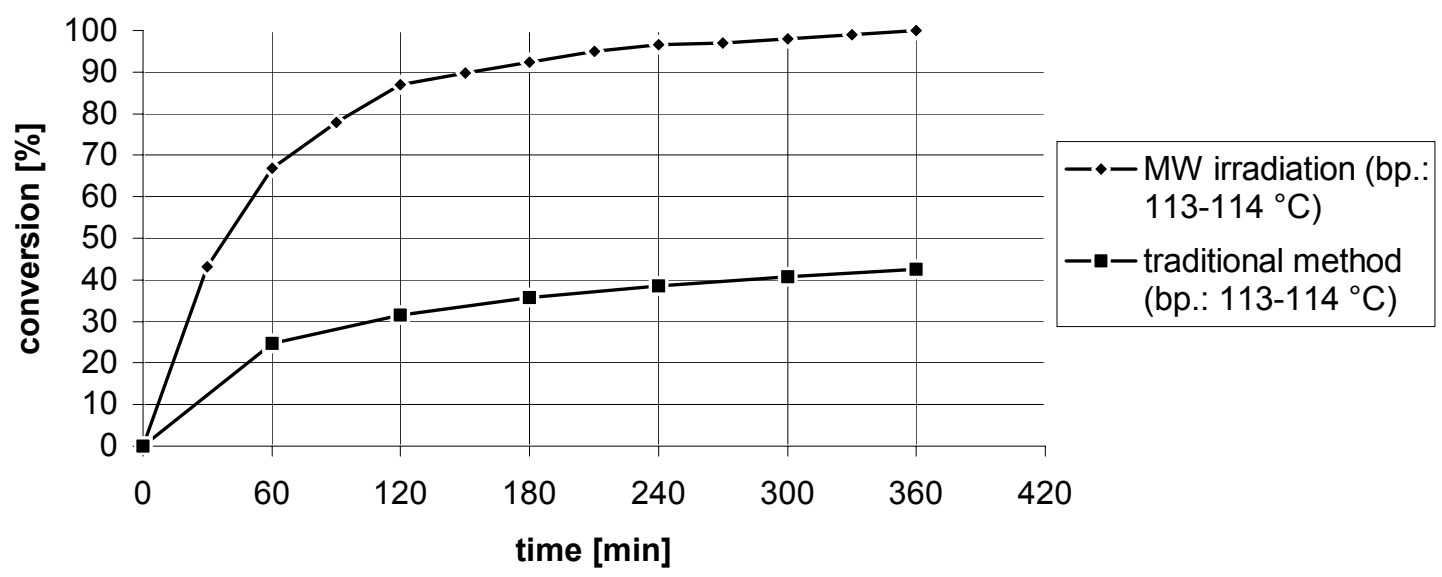

Figure 2. The conversion of 4-chlorobenzophenone (5a) into ketal $6 \mathbf{a}$.

In order to obtain further information on the optimal reaction conditions we have also studied the effect of the ratio of toluene and ethylene glycol $(\mathrm{v} / \mathrm{v})$ in the reaction mixture on the conversion of benzophenone $5 \mathbf{a}$ to ketal $\mathbf{6 a}$. Solutions of ketone $\mathbf{5 a}(0.1 \mathrm{~mol})$ in various mixtures of toluene and ethylene glycol $(0.5 \mathrm{~mol})$ in the presence of PTSA $(0.003 \mathrm{~mol})$ were irradiated with a constant $650 \mathrm{~W}$ energy and small samples were analysed by ${ }^{1} \mathrm{H}$ NMR to determine the conversion. No significant difference was observed in the conversion when the volume of toluene was increased threefold (boiling temperature: $118-120{ }^{\circ} \mathrm{C}$ ) or fivefold (boiling temperature: $113-114^{\circ} \mathrm{C}$ ) over the ethylene glycol (Figure 3).

In both cases $100 \%$ conversion was achieved after $3 \mathrm{~h}$ reaction time. ${ }^{[12]}$ However tenfold (boiling temperature: $112-113{ }^{\circ} \mathrm{C}$ ) excess of toluene decreased the rate of the reaction, it was completed only after $6 \mathrm{~h}$. It is interesting to mention that the conversion exhibited a bell-shaped curve with a maximum at 90 min, when the reaction was carried out in a 1:1 (v/v) mixture of toluene and ethylene glycol. The return of the ketal to the starting ketone was accompanied with the formation of diethylene and triethylene glycol, which were detected in the reaction mixture by ${ }^{1} \mathrm{H}$ NMR. The initial boiling temperature $\left(126^{\circ} \mathrm{C}\right)$ increased to $157^{\circ} \mathrm{C}$ after $90 \mathrm{~min}$.

We investigated the influence of the power of irradiation on the reaction whilst keeping dilution ratios constant (ie. threefold). When applying 400, 650 and $800 \mathrm{~W}$ constant energies no significant difference was detected in the course of the reaction (Figure 4). We noted however that at least $400 \mathrm{~W}$ energy was required to keep the reaction mixture refluxing. However, over $800 \mathrm{~W}$ intensive foaming was observed. 


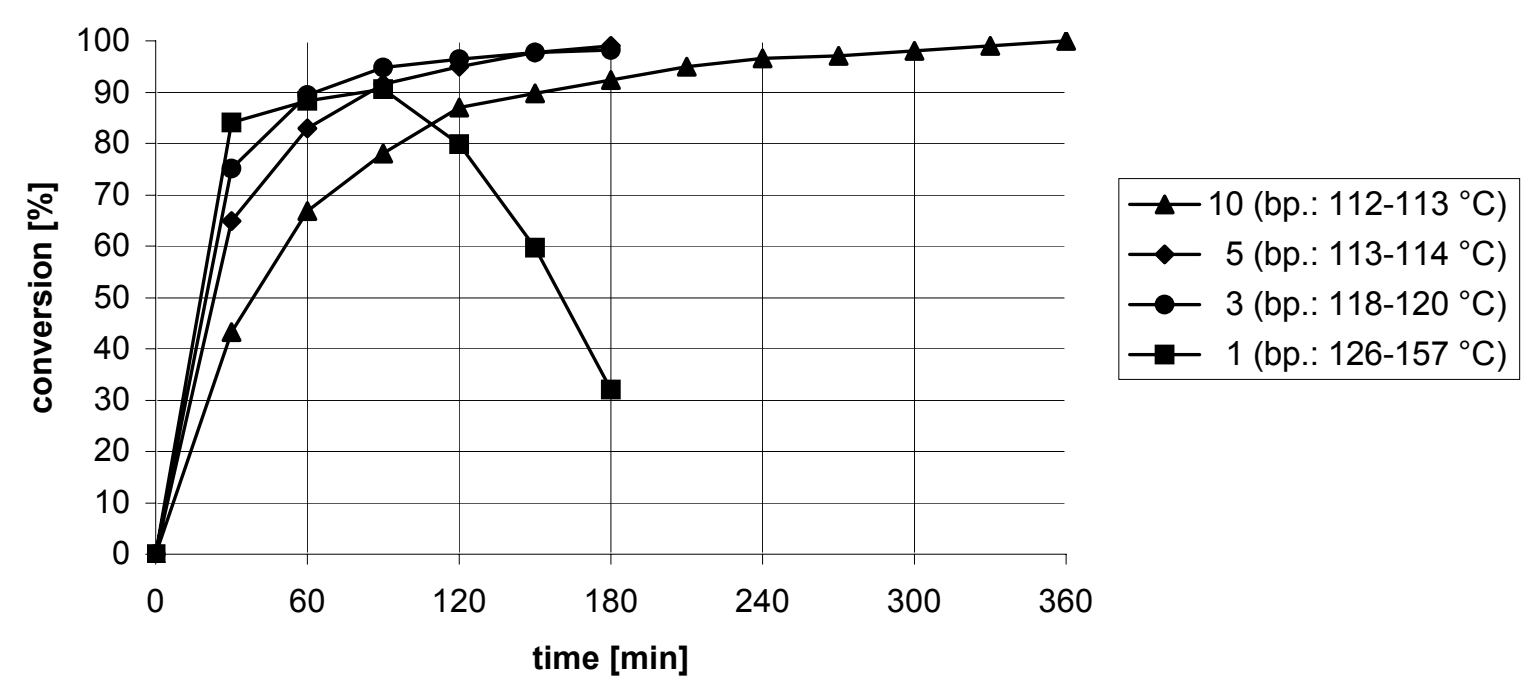

Figure 3. Effect of the toluene / ethylene glycol (v/v) ratio on the conversion of 4chlorobenzophenone (5a) to ethylene ketal $\mathbf{6 a}$.

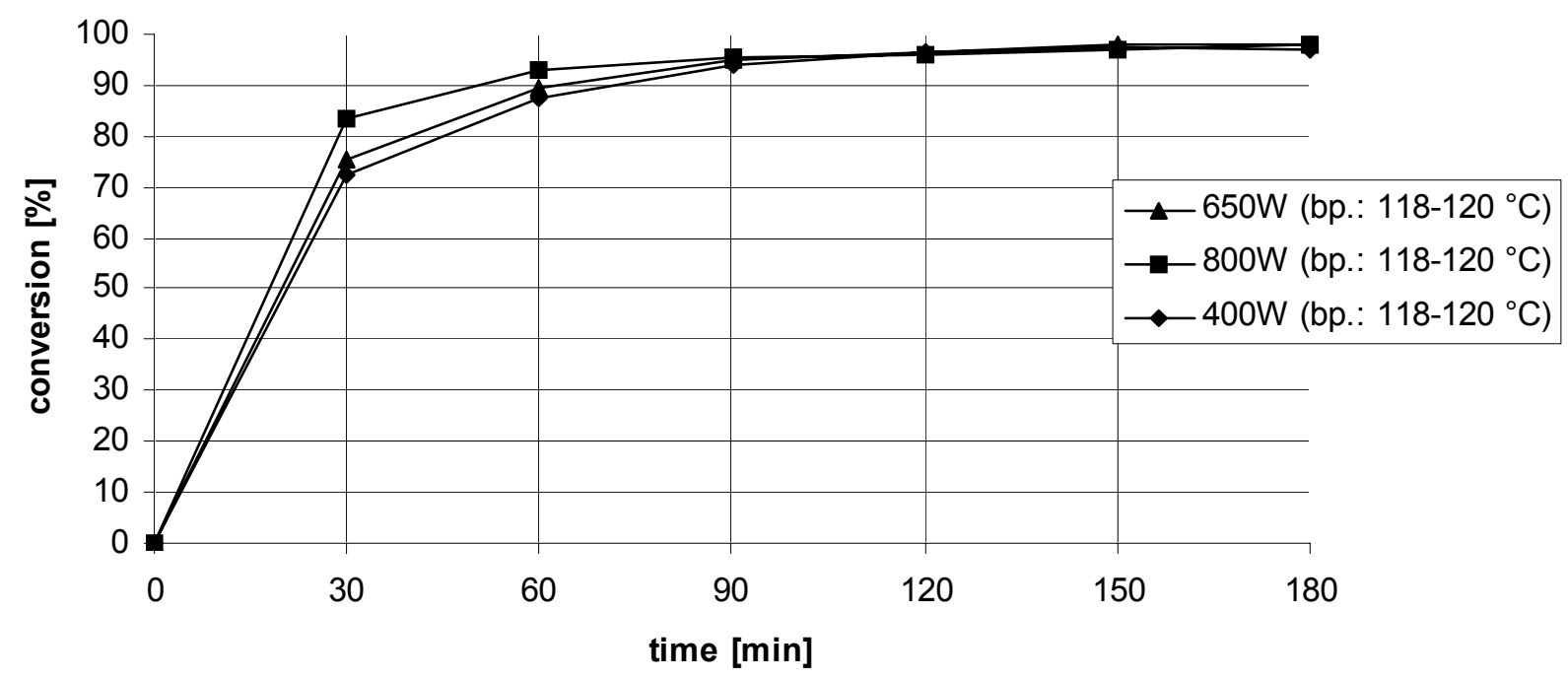

Figure 4. Effect of the microwave power on the conversion of 4-chlorobenzophenone (5a) to ethylene ketal 6a.

With this protocol, solutions of the benzophenones 5a-e $(0.1 \mathrm{~mol})$, ethylene glycol $(31.0 \mathrm{~g}$, $27.9 \mathrm{~mL}, 0.5 \mathrm{~mol})$ and PTSA $(0.57 \mathrm{~g}, 0.003 \mathrm{~mol})$ in toluene $(84 \mathrm{~mL})$ were refluxed (boiling temperature: $118-120^{\circ} \mathrm{C}$ ) in a Dean-Stark apparatus in microwave reactor under irradiation with a constant $650 \mathrm{~W}$ energy for $3 \mathrm{~h}$. After conventional work-up ketals $\mathbf{6 a -}-\mathrm{e}^{[2]}$ were isolated with 92-94 \% yield (Scheme 2). 


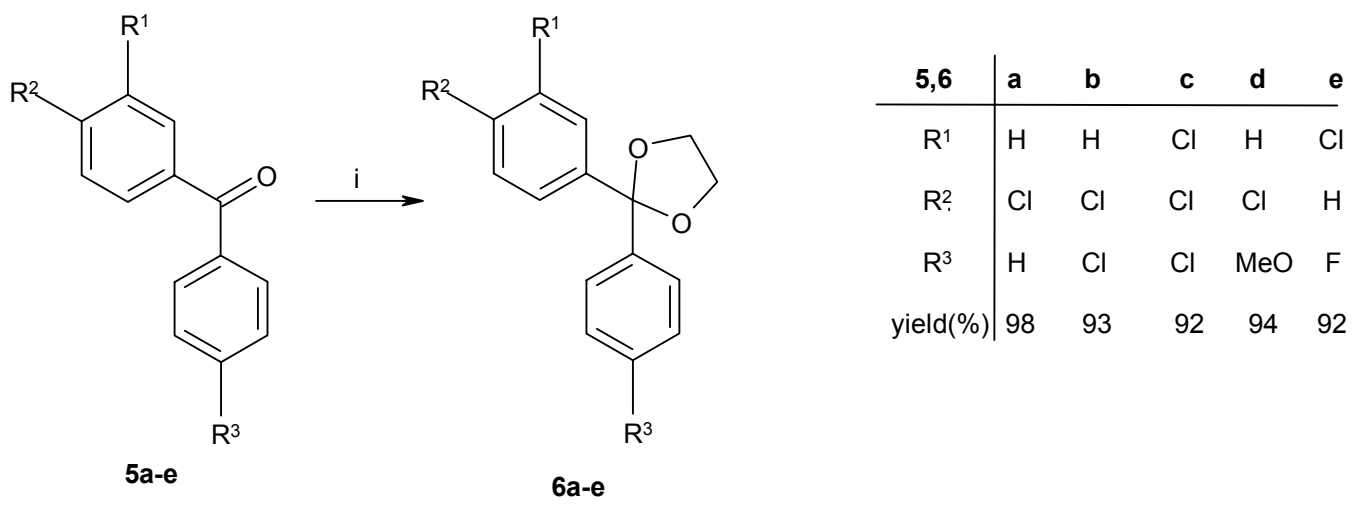

(i) ethylene glycol, PTSA / toluene, MW $650 \mathrm{~W}, 3 \mathrm{~h}$

\section{Scheme 2}

Reacting acetophenones 7 a-e $(0.1 \mathrm{~mol}$, Scheme 3$)$ and using the same amounts of ethylene glycol, PTSA and toluene as above, under irradiation with a constant $500 \mathrm{~W}$ energy and with azeotropic removal of the water, the conversion was complete after $2 \mathrm{~h}$ (boiling temperature: $118-120{ }^{\circ} \mathrm{C}$ ). Ketals 8a-e were isolated with 94-98 \% yield. Compounds 8a,c were characterized as per the literature ${ }^{[1]}$, while $\mathbf{8 b}, \mathbf{d}, \mathbf{e}$ are new compounds (see experimental section).

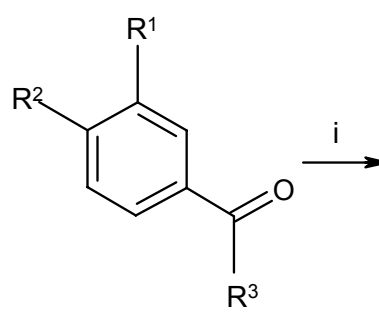

7a-e<smiles>[R]c1ccc(C2([R])OCCO2)cc1[R]</smiles>

8a-e

\begin{tabular}{c|ccccc}
$\mathbf{7 , 8}$ & $\mathbf{a}$ & $\mathbf{b}$ & $\mathbf{c}$ & $\mathbf{d}$ & $\mathbf{e}$ \\
\hline $\mathrm{R}^{1}$ & $\mathrm{H}$ & $\mathrm{H}$ & $\mathrm{Cl}$ & $\mathrm{Cl}$ & $\mathrm{Cl}$ \\
$\mathrm{R}^{2}$ & $\mathrm{Cl}$ & $\mathrm{Cl}$ & $\mathrm{Cl}$ & $\mathrm{Cl}$ & $\mathrm{H}$ \\
$\mathrm{R}^{3}$ & $\mathrm{Me}$ & $\mathrm{Et}$ & $\mathrm{Me}$ & $\mathrm{Et}$ & $\mathrm{Me}$ \\
yield(\%) & 98 & 95 & 96 & 96 & 94
\end{tabular}

(i) ethylene glycol, PTSA / toluene, MW 500 W, 2h

\section{Scheme 3}

In conclusion, a convenient route to acetophenone and benzophenone ethylene ketals has been devised using microwave irradiation and simultaneous removal of the water. Contrary to the traditional methods, high yields were obtained within short reaction times. 


\section{Experimental Section}

General Procedures. Acetophenones 7a-e, 4-chlorobenzophenone 5a were purchased from Aldrich; ethylene glycol, toluene, PTSA from Fluka. Synthesis of benzophenones $\mathbf{5 b},{ }^{[14]} \mathbf{5} \mathbf{c}^{[15]}$ $\mathbf{5 d}{ }^{[16]} \mathbf{5 e},{ }^{[17]}$ was performed according to procedures described in the literature.

All melting points were determined on a Büchi 535 capillary melting point apparatus and are uncorrected. ${ }^{1} \mathrm{H}$ NMR spectra were recorded in $\mathrm{CDCl}_{3}$ on a Varian Gemini-200 or Inova-500 spectrometer using TMS as internal standard. Elemental analyses were performed on a PerkinElmer 2400 analyzer.

\section{Synthesis of 1,3-dioxolanes (8a-e, 6a-e). General procedure}

A solution of acetophenone / benzophenone $(0.1 \mathrm{~mol})$, ethylene glycol $(27.9 \mathrm{~mL}, 31.0 \mathrm{~g}, 0.5$ mol) and PTSA $(0.57 \mathrm{~g}, 0.003 \mathrm{~mol})$ in toluene $(84 \mathrm{~mL})$ was refluxed (boiling temperature: 118 $120^{\circ} \mathrm{C}$ ) in a Dean-Stark apparatus in a microwave reactor under irradiation with a constant 500 $\mathrm{W} / 650 \mathrm{~W}$ energy for $3 \mathrm{~h}$. The reaction mixture was washed with aqueous sodium hydrogen carbonate solution $(5 \%, 30 \mathrm{~mL})$ and water $(2 \times 30 \mathrm{~mL})$, dried $\left(\mathrm{MgSO}_{4}\right)$ and evaporated. The residue was recrystallized or distilled in vacuo. For b.p.'s or m.p.'s, solvents of recrystallization, elemental analyses and ${ }^{1} \mathrm{H}$ NMR data of the ketals $\mathbf{6 a}-\mathbf{e}, \mathbf{8 a}, \mathbf{8 c}$ see literature ${ }^{[1,2]}$ or compounds $\mathbf{8 b}, \mathbf{8 d}, \mathbf{8 e}$ are characterized below.

2-(4-Chloro-phenyl)-2-ethyl-[1,3]dioxolane (8b). $20.2 \mathrm{~g}$ (95\%) as colourless oil, b.p.: 84-86 ${ }^{\circ} \mathrm{C}(0.2 \mathrm{mmHg}) .{ }^{1} \mathrm{H}$ NMR $\left(500 \mathrm{MHz}, 25^{\circ} \mathrm{C}\right): \delta=7.38(2 \mathrm{H}, \mathrm{d}, J=8.4 \mathrm{~Hz}), 7.29(2 \mathrm{H}, \mathrm{d}, J=8.4 \mathrm{~Hz})$, 4.02-3.98 (2H, m), 3.76-3.73 (2H, m), $1.88(2 \mathrm{H}, \mathrm{q}, J=7.4 \mathrm{~Hz}), 0.87(3 \mathrm{H}, \mathrm{t}, J=7.4 \mathrm{~Hz})$. $\mathrm{C}_{11} \mathrm{H}_{13} \mathrm{ClO}_{2}$ (212.68): calcd. C 62.12, $\mathrm{H} \mathrm{6.16,} \mathrm{Cl} \mathrm{16.67;} \mathrm{found} \mathrm{C} \mathrm{62.56,} \mathrm{H} \mathrm{5.98,} \mathrm{Cl} \mathrm{16.48.}$

2-(3,4-Chloro-phenyl)-2-ethyl-[1,3]dioxolane (8d). $23.7 \mathrm{~g}$ (96 \%) as colourless oil, b.p.: 107$110{ }^{\circ} \mathrm{C}(0.6 \mathrm{mmHg}) .{ }^{1} \mathrm{H}$ NMR $\left(500 \mathrm{MHz}, 25^{\circ} \mathrm{C}\right): \delta=7.54(1 \mathrm{H}, \mathrm{d}, J=2.0 \mathrm{~Hz}), 7.40(1 \mathrm{H}, \mathrm{d}, J=8.1$ $\mathrm{Hz}), 7.27(1 \mathrm{H}, \mathrm{dd}, J=8.1 \mathrm{~Hz}, J=2.0 \mathrm{~Hz}), 4.05-3.98(2 \mathrm{H}, \mathrm{m}), 3.79-3.72(2 \mathrm{H}, \mathrm{m}), 1.87(2 \mathrm{H}, \mathrm{q}$, $J=7.3 \mathrm{~Hz}$ ), $0.87(3 \mathrm{H}, \mathrm{t}, J=7.3 \mathrm{~Hz}) . \mathrm{C}_{11} \mathrm{H}_{12} \mathrm{Cl}_{2} \mathrm{O}_{2}$ (247.12): calcd. C 53.46, $\mathrm{H} 4.89, \mathrm{Cl} 28.69$; found C 53.05, H 4.86, $\mathrm{Cl} 28.53$.

2-(3-Chloro-phenyl)-2-methyl-[1,3]dioxolane (8e). $18.7 \mathrm{~g}$ (95\%) as colourless oil, b.p.: 84-85 ${ }^{\circ} \mathrm{C}(0.4 \mathrm{mmHg}) .{ }^{1} \mathrm{H}$ NMR $\left(500 \mathrm{MHz}, 25{ }^{\circ} \mathrm{C}\right): \delta=7.51-7.45(1 \mathrm{H}, \mathrm{m}), 7.40-7.21(3 \mathrm{H}, \mathrm{m}), 4.06-$ $3.99(2 \mathrm{H}, \mathrm{m}), 3.79-3.72(2 \mathrm{H}, \mathrm{m}), 1.63(3 \mathrm{H}, \mathrm{s}) . \mathrm{C}_{10} \mathrm{H}_{11} \mathrm{ClO}_{2}(198.65)$ : calcd. $\mathrm{C} 60.46, \mathrm{H} 5.58, \mathrm{Cl}$ 17.85; found C 60.49, H 5.69, Cl 17.72.

\section{Acknowledgements}

The authors are grateful to Mr. Ferenc Kubovics, managing director of Labsystem Ltd. and his co-workers for the opportunity to test the Milestone MicroSYNTH ${ }^{\circledR}$ microwave reactor. 


\section{References and Notes}

1. Lukács, Gy.; Porcs-Makkay, M.; Simig, Gy. Tetrahedron Lett. 2003, 44, 3211.

2. Lukács, Gy.; Porcs-Makkay, M.; Simig, Gy. Eur. J. Org. Chem. 2004, 4130.

3. Greene, T. W. Protective Groups in Organic Synthesis; Wiley; New York, 1981; p 124.

4. Loewenthal, H. J. E. In Protective Groups in Organic Chemistry; McOmie, J. F. W., Ed.; Plenum: New York, 1973; pp 325-326.

5. Pinder, A. R.; Smith, H. J. Chem. Soc. 1954, 113.

6. Sulzbacher, M.; Bergmann, E.; Pariser, E. R. J. Am. Chem. Soc. 1948, 70, 2827.

7. Mechelke, M. F.; Wiemer, D. F. J. Org. Chem. 1999, 64, 4821.

8. Meskens, F. A. J. Synthesis 1981, 501.

9. Banik, B. K.; Chapa, M.; Marquez, J.; Cardona, M. Tetrahedron Lett. 2005, 46, 2341 and references cited therein.

10. Moghaddam, F. M.; Sharifi, A. Synth. Comm. 1995, 25, 2457.

11. Pério, B.; Dozias, M.-J.; Jacquault, P.; Hamelin, J. Tetrahedron Lett. 1997, 38, 7867.

12. Pourjavadi, A.; Mirjalili, B. F. J. Chem. Res. (S). 1999, 38, 562.

13. The ratio of the starting material and the product was determined on the basis of ${ }^{1} \mathrm{H}$ NMR measurements comparing the intensity of the signals corresponding to four aromatic protons in 5a $(\delta=7.81-7.72 \mathrm{ppm})$ and the four protons of the ketal group in $\mathbf{6 a}(\delta=4.06 \mathrm{ppm})$.

14. Nishida, S. J. Org. Chem. 1967, 32, 2695.

15. Pfister-Guillouzo, G.; Grimaud, M.; Deschamps, J. Bull. Soc. Chim. Fr. 1969, 1212.

16. Kaye, I. A.; Klein, H. C.; Burlant, W. J. J. Am. Chem. Soc. 1953, 75, 745.

17. Pews, R. G.; Tsuno, Y.; Taft, R. W. J. Am. Chem. Soc. 1967, 89, 2391. 